\title{
The Multi-objective Model of Congestion Eliminating Method of Interruptible Load Nodes
}

\author{
Yan Zhang ${ }^{1}$, Jianjun $\mathrm{Xu}^{2,}{ }^{2}$ and Limei Yan ${ }^{2}$ \\ ${ }^{1}$ School of Automation, Baotou Light Industry Vocational Technical College, \\ Baotou, 014035, China \\ ${ }^{2}$ School of Electrical Information \& Engineering, Northeast Petroleum University, \\ Daqing, 163318, China
}

\begin{abstract}
Considering the condition of target selected under different circumstances, this paper proposed a new multi-objective model of transmission congestion management with interruptible load based on brand circuit overload match with interrupt capacity. The objective function of the mathematical model presented in this paper are respectively that, if interruptible load matching with overload capacity, the least number of interruptible load node at least, the lowest total interrupt amount of interruptible load. The multiobject model put forward three goals, brand circuit overload match with interruptible load, the minimum number of interruptible load nodes and the minimum total interruption of interruptible load. Against other optimization methods cannot prioritize to multiple targets and it can easily lead to convergence in the process of solving problems, the paper presented construct evaluation function based on the linear weighted sum to optimize multi-objective linear problem. This method can be sorted prior to multi-objective optimization model. And it has better convergence than other optimization methods in the solution process. Finally, it tested and verified the correctness of method through the IEEE 30 bus power system. And it successfully applied to grid congestion management in oilfield.
\end{abstract}

Keywords: Multi-objective model of transmission congestion; Interruptible load nodes; Branch circuit overload capacity.

\section{Introduction}

The innovation of electric power industry from vertical integrated monopoly to competed market creates a new developmental opportunity for electric power industry, while gives rise to many new problems and challenges such as transmission congestion. It is an important issue. As a route of transporting power, the normal state of transmission network is an important factor on the safety and reliability of system and competition in electric market. With the reform and development of the electricity market, grid load demand is increasing, but transmission congestion phenomenon is the inevitable result of the user load increases. The congestion occurrence will directly affect the normal operation of security and stability of the grid, so the transmission congestion problem has been more and more attention.

Meanwhile, with the opening up of the grid and cross-regional electrical energy trade increasing, the deepening of power market reform, it is necessary to carry out a wider range of optimal allocation of resources. With the growth of demand and the limitation of available transfer capability, the transmission congestion has been an inherent problem in the electricity markets. Transmission congestion may lead to pike price and cause unexpected forced outage of the generator side, which have posed great risk to the distribution company and the end customers. The demand 
side response is one of the effective ways to relieve the congestion. And the gradual opening of demand side has become an important part of congestion management. The increasing of electricity trade and power flow uncertainty has limited the transmission of electrical energy obviously [1]. Consequently, transmission congestion had become an important subject to be solved. With the opening of demanding side, interruptible load can be viewed as a reserve of generation and transmission. It has great effect on relieving the uptight power supply situation. At peak load situation, the interruptible load management provides an effective congestion relieving way by shifting the peak load to low load time segments by using customer power consumption flexibility. On the situation of transmission congestion, taking the initiative and controlled suspending of the supply of interruptible load can relieve transmission congestion and avoid large area blackout.

Using IL (Interruptible Load) to solve the congestion management is a new solution of the congestion management in recent years. IL can make full use of the electricity elasticity, eliminate or relieve congestion and the power supply tension in peak load. According to the interruptible power supply contract signed by the power company and power users, it allows power companies to remove part of the user load as the contracted purview at a particular period of time (such as peak load) [2]. Meanwhile giving the user certain power shortage compensation can reduce the electricity load during peak hours to relieve the tense situation of power supply, thus achieve the purpose of congestion management.

\section{The Calculation of the Maximum Transmission Capacity Based on Opf}

\subsection{Mathematical Model}

Determining the maximum transmission capacity is increasing transmission and reception respectively at a given power generation node(s) and the load node(s), then solving power flow equations and checking whether there is an overload line or out of node voltage out-of-limit, repeating the process until appearing the overload line or out-of-limit node. Therefore, the mathematical model is as follows:

$$
\begin{gathered}
\max \lambda_{d} \\
\text { s.t. } g\left(x, \lambda_{d}\right)=0 \\
h(x) \leq 0
\end{gathered}
$$

$\lambda_{d}$ is a real parameter variable, reflecting the system transmission capacity of the node load and generator power in a given varying modes. $g\left(x, \lambda_{d}\right)=g(x)+\lambda_{d} b_{d}, b_{d}$ injects the varying direction vector for system nodes power.

\subsection{Calculation Process and Result}

IEEE-30 bus system [3] is calculated with the method based on the trust region interior point method for the above mathematical model. Branches connection of the system is shown in Figure (1), a total of 6 generators, 37 branches.

The basic parameters of the system are as follows: 6 generators, 37 branches, active load 2.8340MW, reactive load 1.2620MVAR, initial net loss $7.09 \mathrm{MW}$, the objective function is the system node load. Relevant parameters of the algorithm is set to: the initial trust region radius $\Delta o=0.4$, penalty parameter $\sigma=10.0$, related parameters of adjusting the trust region radius of $\rho_{1}=0.5, \rho_{2}=0.6, \rho_{3}=0.8$, 
convergence criterion $\varepsilon=0.01$, convergence criterion of LP sub-problems $\varepsilon_{L P} \leq 0.001$. The results are shown in Table 1 and Table 2 below.

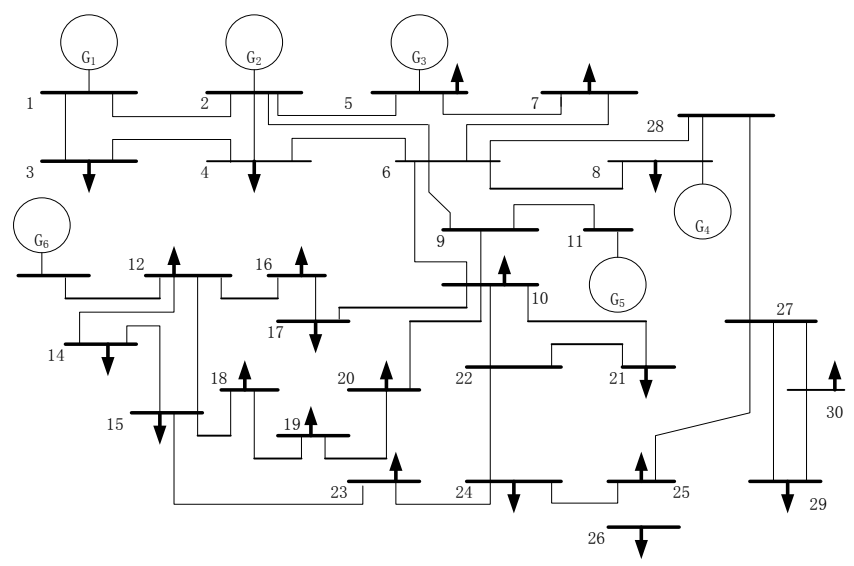

Figure 1. IEEE 30 Bus System

Table 1. Results of Power Node in Zone 2 and Load Node in Zone 1(MW)

\begin{tabular}{|c|c|c|c|c|c|c|c|}
\hline Node & 13 & 23 & 2 & 3 & 4 & 7 & 8 \\
\hline Result & 35.04 & 30.81 & 37.31 & 4.13 & 13.07 & 39.20 & 51.58 \\
\hline
\end{tabular}

The results can be seen by using OPF method can accurately calculate the maximum transmission capacity of the branch, thus determine the out-of-limit branch, and lay the foundation of using interruptible load to eliminate congestion.

Table 2. Calculation Results of Maximum Transmission Capacity from Power Node to Load Node

\begin{tabular}{|l|c|c|c|}
\hline & Active Power & Active Node & $\begin{array}{c}\text { Power Flow Out-of-limit } \\
\text { Branch }\end{array}$ \\
\hline Calculation Result & 65.85 & 167.05 & $6-8,21-22,23-24$ \\
\hline
\end{tabular}

\section{The Transmission Congestion Management Model based on Branch Load}

This paper divides congestion eliminating scheme into three different cases, sorting matching capacity, interruptible capacity and choosing amount respectively, to eliminate congestion by choosing interruptible load reasonably [4-5].

(1). In the cases of load amount of interruptible load contracts signed not identical and matching with the branch circuit overload, interruptible load matching with load amount should be selected. Model representation is as follows:

$$
\min f_{1}=P_{i}, i=1,2, \ldots, N_{1}
$$

In the formula, $P_{i}$ indicates the ith load amount matching with the overload.

(2). In the cases of multiple identical capacity interruptible load and these load capacity matching with branch circuit load, interrupt node should be selected as little as possible, meaning to select the minimum interrupt amount of interruptible load users at the same time. Shown as follow:

$$
\min f_{2}\left(P_{i}\right)=\min \sum_{i}^{N_{i}} P_{i}\left(K_{i}\right), i=1,2, \ldots, N_{1}
$$

(3). On the condition that no load capacity in all contracts signed interruptible load matching with branch circuit load, the load reduction should not increase the 
burden on the ISO. Hope that under a certain amount of compensation, the total load reductions as few as possible to eliminate the congestion, i.e., according to select the least interruptible load amount of the scheme as objective function, model representation is as follows:

$$
\min f_{3}\left(\Delta P_{d i}\right)=\min \sum_{i}^{N_{1}} \Delta P_{d i}
$$

The constraints of the mathematical model presented in this paper can be represented as inequality:

Load interruption amount constraint

$$
\Delta P_{d i} \leq \Delta P_{d i}^{\max }
$$

Branch transmission capacity constrain

Generating capacity constraint

$$
P_{i j} \leq P_{i j}^{\max }
$$

$$
P_{g i}^{\min } \leq P_{g i} \leq P_{g i}^{\max } \quad i \in\left[1,2, \ldots, N_{g}\right]
$$

In the formula, $P_{g i}^{\min }, P_{g i}^{\max }$ are separately the upper and lower limit value of active power output of the node i generator.

Operating reserve capacity constraint

$$
\sum_{i}^{N_{g}} P_{g i}^{\max } \cdot T_{i}-\sum_{i}^{N} P_{d i}+\sum_{i}^{N_{1}} \Delta P_{d i} \geq R
$$

The above formula indicates that capacity margin of power system operating environment. To ensure system reliability, the value cannot less than the minimum value $\mathrm{R}$; the value is generally $5 \%$ of the total system load. $T_{i}$ is $0-1$ variable, which represents if generator generates. $N_{g}$ is total number generators, $P_{g i}^{\max }$ is the maximum active power output of the node i generator.

\section{The Solution to Objective Model based on Constructing Evaluation Function Method}

The method is based on the decision maker's preferences of each objective function to give each goal certain weights. It is expressed as follows:

$$
\min \lambda^{T} f(x)=\sum_{j=1}^{m} \lambda_{j} f_{j}(x)
$$

In the formula, $f(x)=\left(f_{1}(x), \ldots, f_{m}(x)\right)^{T}, \quad \lambda=\left(\lambda_{1}, \ldots, \lambda_{m}\right) . \lambda_{1}, \ldots, \lambda_{m}$ is a set of weight coefficients, reflecting a preference of decision makers. The weight coefficients change in a certain range, so as to get effective solution set.

This paper has three objective functions, in accordance with the matching degree between overload capacity and interruptible load to construct a mathematical model by using linear weighted sum method, which is expressed as follows:

$$
F(X)=\sum_{i=1}^{L} \omega_{i} f_{i}(x), X=\left(x_{1}, x_{2}, \ldots, x_{n}\right)^{T}
$$

In the formula, $f_{i}(x)$ is each objective function; $\omega_{i}$ is a set of weight coefficients.

Evaluation function constructed by using the linear weighted sum method is shown as follows:

$$
\begin{gathered}
F=\omega_{1} f_{1}+\omega_{2} f_{2}+\omega_{3} f_{3} \\
F=\omega_{1} P_{i}+\omega_{2}\left(K_{1}+K_{2}+\cdots+K_{N_{1}}\right)+\omega_{3} \Delta P
\end{gathered}
$$


Solving the optimal solution of this kind of evaluation function has the following theorems:

Setting $X^{*} \in D \quad(D$ is feasible region), if for any $X \in D$, $f_{i}\left(X^{*}\right) \leq f_{i}(X)(i=1,2, \ldots, n)$ sets up all the time, then calling $X^{*}$ as absolute optimal solution for the objective function, the optimal solution for short.

Specifically, corresponding model VMP, it is set feasible region as $X$, each objective function $f_{j}(x)$, set the minimum point $x^{j}$ in the feasible region:

$$
f_{j}\left(x^{j}\right)=\min _{x \in X} f_{j}(x), j=1,2, \ldots, m
$$

Using $x^{j}$ can calculate $m^{2}$ target value, namely

$$
f_{i j}=f_{j}\left(x^{i}\right), i, j=1,2, \ldots, m
$$

Introducing auxiliary parameter $\alpha$, to list $m+1$ order equations of $\omega_{i}(i=1,2, \ldots, m)$ and $\alpha$ in (13)

$$
\left\{\begin{array}{l}
\sum_{i=1}^{m} f_{i j} \omega_{i}=\alpha, j=1,2, \ldots, m \\
\sum_{i=1}^{m} \omega_{i}=1
\end{array}\right.
$$

\section{Validation of the ieee-30 Node System}

This paper takes IEEE-30 node system as an example to simulate is shown in Table 3.

Assuming that the user is rational, who can report interruptible load according to the amount of power shortage. The nodes where users participating in congestion management and interruptible load amount of users are shown in Table 4.

Table 3. Each Node Load Parameter of IEEE-30 Node System

\begin{tabular}{|c|c|c|c|c|c|}
\hline \multirow{2}{*}{$\begin{array}{c}\text { Node } \\
\text { Number }\end{array}$} & \multicolumn{2}{|c|}{ Node Amount } & Node & \multicolumn{2}{c|}{ Node Amount } \\
\cline { 2 - 3 } \cline { 5 - 6 } & MW & MVAR & Number & MW & MVAR \\
\hline 1 & 0.0 & 0.0 & 16 & 3.5 & 1.8 \\
\hline 2 & 21.7 & 12.7 & 17 & 9.0 & 5.8 \\
\hline 3 & 2.4 & 1.2 & 18 & 3.2 & 0.9 \\
\hline 4 & 7.6 & 1.6 & 19 & 9.5 & 3.4 \\
\hline 5 & 94.2 & 19.0 & 20 & 2.2 & 0.7 \\
\hline 6 & 0.0 & 0.0 & 21 & 17.2 & 11.2 \\
\hline 7 & 22.8 & 10.9 & 22 & 0.0 & 0.0 \\
\hline 8 & 30.0 & 30.0 & 23 & 3.2 & 1.6 \\
\hline 9 & 0.0 & 0.0 & 24 & 8.7 & 6.7 \\
\hline 10 & 5.8 & 2.0 & 25 & 0.0 & 0.0 \\
\hline 11 & 0.0 & 0.0 & 26 & 0.0 & 0.0 \\
\hline 12 & 11.2 & 7.5 & 27 & 0.0 & 0.0 \\
\hline 13 & 0.0 & 0.0 & 28 & 0.0 & 0.0 \\
\hline 14 & 6.2 & 1.6 & 29 & 2.4 & 0.9 \\
\hline 15 & 8.2 & 2.5 & 30 & 10.6 & 1.9 \\
\hline
\end{tabular}




\section{Table 4. Maximum Interruptible Load of Users}

\begin{tabular}{|c|c|}
\hline Node & $\Delta P_{d i}^{\max }(M W)$ \\
\hline 5 & 28.26 \\
\hline 7 & 6.84 \\
\hline 21 & 5.25 \\
\hline 23 & 0.96 \\
\hline 24 & 2.61 \\
\hline 26 & 1.05 \\
\hline 30 & 3.18 \\
\hline
\end{tabular}

Table 5. Over Slip and Overload Capacity of Three Cases

\begin{tabular}{|c|c|c|c|}
\hline \multirow{2}{*}{$\begin{array}{c}\text { Over } \\
\text { Slip }\end{array}$} & \multicolumn{3}{|c|}{ Overload Capacity(MW) } \\
\cline { 2 - 4 } & Case1 & Case 2 & Case 3 \\
\hline $1-2$ & 123.95 & 102.50 & 180.34 \\
\hline $1-3$ & 40.78 & 38.83 & 0 \\
\hline $2-4$ & 18.63 & 10.18 & 47.60 \\
\hline $3-4$ & 13.03 & 6.53 & 0 \\
\hline $2-5$ & 0 & 0 & 72.24 \\
\hline $2-6$ & 49.43 & 40.98 & 54.03 \\
\hline $4-6$ & 27.18 & 45.18 & 7.31 \\
\hline TOTAL & 273.00 & 244.01 & 289.27 \\
\hline
\end{tabular}

Overload branch circuit and overload capacity of the system are determined in three different cases by power flow calculation. As shown in Table 5, three cases were: in normal operating condition, the transmission lines appear congestion; generator G6 unexpectedly power outage, transmission lines appear congestion; the overloaded branches of 1-3 nodes disconnect, transmission lines appear congestion [6-7].

\subsection{The Relief of the Line Congestion in the Normal Operation}

In this paper, in verifying to IEEE-30 system, it should first consider the optimizing situation of single objective (brand circuit overload match with interruptible load, the minimum number of total interrupt amount and the minimum number of interruptible load users), and calculate the case of optimizing multiobjective composed three single objective as the objective function to get selection scheme of interruptible load based on constructing evaluation function [8-10]. Interruption scheme obtained by calculation and analysis are shown in Table 6; and then analyzing calculation result by comparison to obtain Table 7.

From the results can be seen: when the objective function is the minimum number of interruptible load users, total interrupt amount of a set of interruptible users selected by ISO reaches maximum. When the objective function is the minimum of total interrupt amount, the number of interruptible load users doesn't reach the minimum. The calculation result of the mathematical model of interruptible load can be seen that, the number of interruptible load users reaches minimum, the total interrupt amount close to the minimum. So, the result is optimal.

In traditional multi-objective optimization method, the most widely used is the fuzzy optimization method. This paper will compare the calculated results of the multi-objective optimization scheme calculated by the fuzzy optimization method with being based on constructing evaluation function method. The comparative result is shown in Table 8 .

As can be seen from Table 8, the total interrupt amount of interruptible load of the multi-objective optimization method using fuzzy optimization method is 8.902 MW, and the total interrupt amount in constructing evaluation function method is $8.786 \mathrm{MW}$. The number of interrupt nodes is same 4, but the total interrupt amount has reduced obviously. You can see the interruptible load selection scheme based on constructing evaluation function method being better than fuzzy optimization method. 


\subsection{The Relief of the Line Congestion in the Unexpected Outage}

When the generator unexpectedly shut down, transmission system also will appear congestion. IEEE-30 bus system consists of 6 generators. This paper assumes G6 shut down unexpectedly; in this case, it is solved separately according to the single objective and multi-objective function to get the cutting interrupt load scheme shown in Table 9. The comparative summary result is shown in Table 10.

Analyzing Table 10 can see that: when the objective function is the minimum number of interruptible load users, total interrupt amount of a set of interruptible users selected by ISO closes to the maximum; when the objective function is according to if the overload matching, the number of interruptible load users reaches the maximum; when the objective function is the minimum number of interruptible load, the number of interrupt users reaches the maximum, the results are not very satisfactory. In the results obtained by linear weighted model, the total interrupt amount is not the lowest, but close to the minimum; the number of interrupt users reaches the minimum, taken together, the selection of interruptible load is still the best results.

The result of comparing the interruptible load selection scheme of fuzzy optimization with being based on constructing evaluation function method is shown in Table 11.

As can be seen from Table 11, the total interrupt amount of two optimization approaches is $9.207 \mathrm{MW}, 9.381 \mathrm{MW}$. The values is so close, but the interrupt number selected by the optimized scheme applying the constructing evaluation function method is 4 , the interrupt number of using fuzzy optimization method is 5 , so the selected scheme is obviously better than the fuzzy optimization method.

\subsection{The Relief of the Line Congestion when Branch Accidentally Disconnected}

Another case of the line congestion is a branch node in transmission line suddenly disconnected. Solving the single-objective mathematical model and the multiobjective mathematical model twice to get the selected scheme of interruptible load by calculating is shown in Table 12; the summary of calculated result is shown in Table 13.

Table 6. Reduction Interruptible Load Program in Normal Operation

\begin{tabular}{|c|c|c|c|c|}
\hline \multirow{2}{*}{ Node } & \multicolumn{4}{|c|}{ IL Interrupt Amount(MW) } \\
\cline { 2 - 5 } & $f_{1}$ & $f_{2}\left(K_{i}\right)$ & $f_{3}\left(\Delta P_{d i}\right)$ & $\begin{array}{c}\text { Multi- } \\
\text { objective }\end{array}$ \\
\cline { 2 - 5 } & 1.158 & 0.159 & 0.159 & 1.158 \\
\hline 5 & 0 & 0.630 & 0.630 & 0 \\
\hline 7 & 4.174 & 5.250 & 4.174 \\
\hline 21 & 5.250 & 4.174 & 0.960 \\
\hline 23 & 0 & 0.960 & 0.960 & 2.610 \\
\hline 24 & 2.610 & 2.610 & 0 & 0 \\
\hline 26 & 0 & 0 & 1.050 & 0 \\
\hline 30 & 0.575 & 0 & 1.449 & \multicolumn{2}{c}{} \\
\hline
\end{tabular}


Table 7. Result of Normal Operating Condition

\begin{tabular}{|c|c|c|c|c|}
\hline \multirow{2}{*}{$\begin{array}{c}\text { Objective } \\
\text { Function }\end{array}$} & \multicolumn{3}{|c|}{ Single Objective } & Multi-objective \\
\cline { 2 - 5 } & $f_{1}$ & $f_{2}\left(K_{i}\right)$ & $f_{3}\left(\Delta P_{d i}\right)$ & $F(x)$ \\
\hline Overload Capacity & 8.435 & 8.347 & 9.339 & 7.744 \\
\hline $\begin{array}{c}\text { Total Interrupt } \\
\text { Amount }\end{array}$ & 9.593 & 8.533 & 9.498 & 8.786 \\
\hline Interrupt Number & 4 & 5 & 6 & 4 \\
\hline Interrupt Branch & $2-5$ & $2-4$ & $1-3$ & $2-5$ \\
\hline
\end{tabular}

Table 8. Comparative Result of two Multi-objective Optimization Approaches

\begin{tabular}{|c|c|c|}
\hline & $\begin{array}{c}\text { Constructing Evaluation Function } \\
\text { Method }\end{array}$ & Fuzzy Optimization Method \\
\hline Total Interrupt Amount & 8.786 & 8.902 \\
\hline Interrupt Number & 4 & 4 \\
\hline
\end{tabular}

From Table 13 can be seen: by the former two kinds of analysis procedures, the number of interruptible load users obtained by the mathematical model proposed in this paper closes to the minimum, the total interrupt amount is ideal. Therefore the result obtained by the model is still the best.

The constructing evaluation function method and the fuzzy optimization method are compared to work out the total interrupt amount and interrupt number of interruptible load as shown in Table 14. As can be seen from the table, the total interrupt amount calculated by constructing evaluation function method is $9.208 \mathrm{MW}$, higher than it in fuzzy optimization method, but the interrupt number less than fuzzy optimization method. To ensure interruptible load selected scheme programs is optimal, price and other factors are also important indicators affecting the ISO selecting interruptible load.

Table 9. Interruptible Load Cut Program in the Outage

\begin{tabular}{|c|c|c|c|c|}
\hline \multirow{3}{*}{ Node } & \multicolumn{4}{|c|}{ IL Interrupt Amount(MW) } \\
\hline & \multicolumn{3}{|c|}{ Single Objective } & Multi-objective \\
\hline & $f_{1}$ & $f_{2}\left(K_{i}\right)$ & $f_{3}\left(\Delta P_{d i}\right)$ & $F(x)$ \\
\hline 5 & 0.774 & 0 & 0 & 0 \\
\hline 7 & 0 & 0.219 & 0.219 & 0.219 \\
\hline 21 & 5.250 & 5.250 & 5.250 & 5.250 \\
\hline 23 & 0 & 0 & 0.807 & 0 \\
\hline 24 & 2.610 & 2.610 & 0 & 2.610 \\
\hline 26 & 1.050 & 1.050 & 1.050 & 0 \\
\hline 30 & 0 & 0.186 & 2.425 & 1.302 \\
\hline
\end{tabular}

Table 10. Result of G6 Outage

\begin{tabular}{|c|c|c|c|c|}
\hline \multirow{2}{*}{ Objective Function } & \multicolumn{3}{|c|}{ Single Objective } & Multi-objective \\
\cline { 2 - 5 } & $f_{1}$ & $f_{2}\left(K_{i}\right)$ & $f_{3}\left(\Delta P_{d i}\right)$ & $F(x)$ \\
\hline Overload Capacity & 9.250 & 9.053 & 9.554 & 9.171 \\
\hline $\begin{array}{c}\text { Total Interrupt } \\
\text { Amount }\end{array}$ & 9.684 & 9.315 & 9.751 & 9.207 \\
\hline Interrupt Number & 4 & 5 & 5 & 4 \\
\hline Interrupt Branch & $3-4$ & $2-5$ & $1-3$ & $3-4$ \\
\hline
\end{tabular}




\section{Table 11. Comparative Result of two Multi-objective Optimization Approaches when Generator Unexpectedly Shut Down}

\begin{tabular}{|c|c|c|}
\hline $\begin{array}{c}\text { Generator } \\
\text { Unexpectedly Shut } \\
\text { Down }\end{array}$ & $\begin{array}{c}\text { Constructing Evaluation } \\
\text { Function Method }\end{array}$ & Fuzzy Optimization Method \\
\hline Total Interrupt Amount & 9.207 & 9.381 \\
\hline Interrupt Number & 4 & 5 \\
\hline
\end{tabular}

Table 12. Interruptible Load Cut Program of 1-3 Branch Cuts

\begin{tabular}{|c|c|c|c|c|}
\hline \multirow{2}{*}{ Node } & \multicolumn{4}{|c|}{ IL Interrupt Amount(MW) } \\
\cline { 2 - 5 } & \multicolumn{3}{|c|}{ Single Objective } & Multi-objective \\
\cline { 2 - 5 } & $f_{1}$ & $f_{2}\left(K_{i}\right)$ & $f_{3}\left(\Delta P_{d i}\right)$ & $F(x)$ \\
\hline 5 & 1.906 & 0.352 & 0.352 & 1.906 \\
\hline 7 & 0 & 0.980 & 0.980 & 0 \\
\hline 21 & 4.743 & 1.910 & 5.204 & 5.202 \\
\hline 23 & 0 & 0.960 & 0.960 & 0.960 \\
\hline 24 & 2.610 & 2.610 & 0 & 0 \\
\hline 26 & 0 & 1.050 & 1.048 & 0 \\
\hline 30 & 0 & 0 & 0 & 1.050 \\
\hline
\end{tabular}

\section{The Application of Grid Congestion Management in Oil Field}

As shown in Figure (2), The condition of load of each substation provided by power company is the maximum load of the whole grid between 2007-2008, namely the date at 18:00 on the January 15,2008 , which was enlarged to $300 \%$, to simulate the condition appearing circuit congestion, partial load data as shown in Table 15.

Table 13. Result of 1-3 Branch-off

\begin{tabular}{|c|c|c|c|c|}
\hline \multirow{2}{*}{ Objective Function } & \multicolumn{3}{|c|}{ Single Objective } & Multi-objective \\
\cline { 2 - 5 } & $f_{1}$ & $f_{2}\left(K_{i}\right)$ & $f_{3}\left(\Delta P_{d i}\right)$ & $F(x)$ \\
\hline Overload Capacity & 9.250 & 7.862 & 8.544 & 9.118 \\
\hline $\begin{array}{c}\text { Total Interrupt } \\
\text { Amount }\end{array}$ & 9.259 & 7.863 & 8.545 & 9.208 \\
\hline Interrupt Number & 3 & 6 & 5 & 4 \\
\hline Interrupt Branch & $4-6$ & $1-2$ & $2-4,3-4$ & $1-2,2-4$ \\
\hline
\end{tabular}

Table 14. Comparative Result of two Multi-objective Optimization Approaches when Branch Accidentally Disconnected

\begin{tabular}{|c|c|c|}
\hline $\begin{array}{c}\text { Branch } \\
\text { Accidentally } \\
\text { Disconnected }\end{array}$ & $\begin{array}{c}\text { Constructing Evaluation Function } \\
\text { Method }\end{array}$ & Fuzzy Optimization Method \\
\hline $\begin{array}{c}\text { Total Interrupt } \\
\text { Amount }\end{array}$ & 9.208 & 9.118 \\
\hline $\begin{array}{c}\text { Interrupt } \\
\text { Number }\end{array}$ & 4 & 5 \\
\hline
\end{tabular}




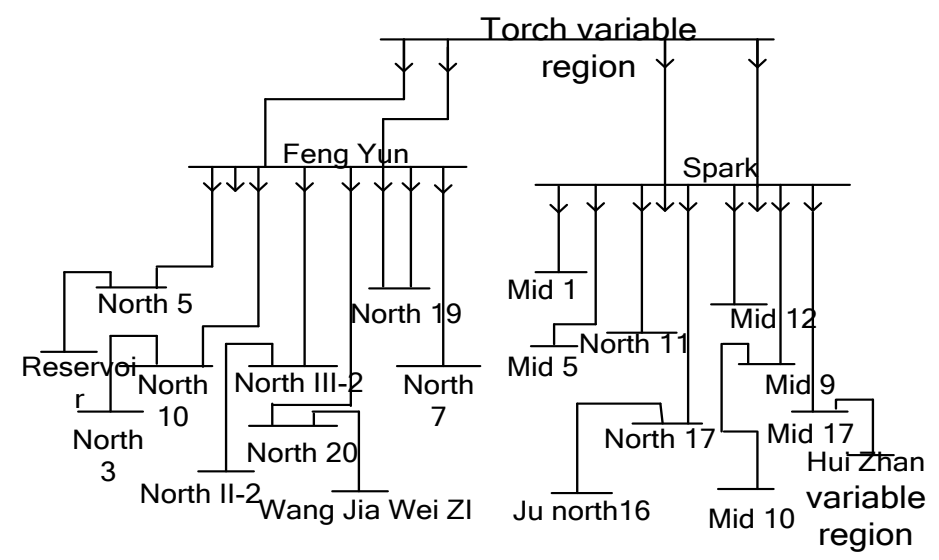

Figure 2. Node Roadmap of Torch Variable Region

As shown in Figure 2, there are 24 branches in torch variable region. Each branch is numbered, and each branch parameter is listed, as shown in Table 16.

The torch variable region of this oil grid is power flow calculated, and the overload branch and overload capacity under three different conditions are calculated separately, as shown in Table 17. Three conditions are as follows: in normal operating condition, transmission lines appear congestion; Feng Yun variable region power outage, transmission lines appear congestion; branch circuit 15 unexpectedly disconnect, transmission lines appear congestion.

This paper calculates and analyzes the torch variable region of this oil grid, simulates transmission congestion in three cases, compares and analyzes the selected scheme of solving three separate single objective function and multi-objective function.

\subsection{The Selected Scheme of Interruptible Lode in Normal Operating Condition}

As can be seen from the result, the selection condition is single objective. When the minimum number of interruptible load users is objective function (that is, the objective function), the total interrupt amount of interruptible users is $6.587 \mathrm{MW}$, up to the maximum. When the minimum total interrupt amount is objective function, it is $5.860 \mathrm{MW}$, and the number of interruptible load users is 3 , not up to the minimum. When the multi-objective function as interruptible load selected objective function is solved, as shown in Table 18, the number of interruptible load users of the selected scheme is the minimum. The total interrupt amount does not reach the minimum, but closes to the minimum. So, selected scheme is the best.

\subsection{Congestion Eliminating Scheme of Unexpected Power Outage}

Table 19 can be analyzed that: if the total interrupt amount of interruptible load is the objective function, the branch overload can be eliminated effectively, but the interrupt number will reach the maximum. In multi-objective optimization conditions, the selected result of interruptible load scheme obtained by the objective function model given in this paper, the number of interrupt users is 2 , and total interrupt amount is $6.442 \mathrm{MW}$, also close to the minimum. And the branch overload can be effectively eliminated. The selected result of interruptible load is the best. 
Table 15. Torch Part of Load Condition

\begin{tabular}{|c|c|c|c|}
\hline \multicolumn{4}{|c|}{ Statistics of Power Company Substation Load Jurisdiction } \\
\hline Substation Name & Measuring Position & \multicolumn{2}{c|}{} \\
\hline $\begin{array}{c}\text { Tou Tai Once } \\
\text { Substation }\end{array}$ & 110KV Inlet Wire Name & $\begin{array}{c}\text { Active Power } \\
\text { (KW) }\end{array}$ & $\begin{array}{c}\text { Reactive Power } \\
\text { (KVAR) }\end{array}$ \\
\hline & Source Line A 01106 & 48 & 15 \\
\hline & Source Line B 01107 & 48 & 15 \\
\hline & 35KVInlet Wire Name & & 9 \\
\hline & Tai Zhao Line A 01137 & 33 & 1.5 \\
\hline & Song Yi Line 01140 & 3 & 1.5 \\
\hline & Ao Nan Line A 01139 & 3 & 0.6 \\
\hline & Ao Nan Line B 01142 & 33 & 12 \\
\hline & $\begin{array}{c}\text { No. 1 Main Transformer } \\
\text { 6(10)KV Switch }\end{array}$ & 24 & 0 \\
\hline & $\begin{array}{c}\text { No. 2 Main Transformer } \\
\text { 6(10)KV Switch }\end{array}$ & 0 & \\
\hline
\end{tabular}

Table 16. Branch Capacity Parameter of Torch Variable Region

\begin{tabular}{|c|c|c|c|c|c|}
\hline $\begin{array}{c}\text { Branch } \\
\text { Number }\end{array}$ & Branch Name & $\begin{array}{c}\text { Reference } \\
\text { Value(MVA) }\end{array}$ & $\begin{array}{c}\text { Branch } \\
\text { Number }\end{array}$ & $\begin{array}{c}\text { Branch } \\
\text { Name }\end{array}$ & $\begin{array}{c}\text { Reference } \\
\text { Value } \\
\text { (MVA) }\end{array}$ \\
\hline 1 & Torch-Feng Yun I & 50 & 13 & $\begin{array}{c}\text { Torch-Spark } \\
\text { I }\end{array}$ & 12 \\
\hline 2 & Torch-Feng Yun II & 34 & 14 & $\begin{array}{c}\text { Torch-Spark } \\
\text { II }\end{array}$ & 26 \\
\hline 3 & Feng Yun-North 5 & 50 & 15 & Spark-Mid 1 & 26 \\
\hline 4 & North 5-Reservoir & 50 & 16 & Spark-Mid 5 & 26 \\
\hline 5 & Feng Yun-North 10 & 34 & 17 & $\begin{array}{c}\text { Sparke- } \\
\text { North 11 }\end{array}$ & 26 \\
\hline 6 & North 10-North 3 & 50 & 18 & $\begin{array}{c}\text { Spark-North } \\
17\end{array}$ & 26 \\
\hline 7 & Feng Yun-North III2 & 34 & 19 & $\begin{array}{c}\text { North 17-Ju } \\
\text { North 16 }\end{array}$ & 26 \\
\hline 8 & North III2-North II2 & 50 & 20 & $\begin{array}{c}\text { Spark-Mid } \\
12\end{array}$ & 12 \\
\hline 9 & Feng Yun-North 20 & 34 & 21 & Spark-Mid 9 & 12 \\
\hline 10 & North 20-Wang Jia & 56 & 22 & $\begin{array}{c}\text { Mid 9-Mid } \\
10\end{array}$ & 12 \\
\hline 11 & Feng Yun-North 19 & 26 & 23 & $\begin{array}{c}\text { Spark-Mid } \\
17\end{array}$ & 12 \\
\hline 12 & Feng Yun-North 7 & 56 & 24 & $\begin{array}{c}\text { Mid 17-Hui } \\
\text { Zhan }\end{array}$ & 12 \\
\hline
\end{tabular}

Table 17. Overload Slip and Capacity of Three Cases

\begin{tabular}{|c|c|c|c|}
\hline \multirow{2}{*}{ Overload Slip Number } & \multicolumn{3}{|c|}{ Overload Capacity(MW) } \\
\cline { 2 - 4 } & Case 1 & Case 2 & Case 3 \\
\hline 1 & 47.50 & 37.27 & 65.77 \\
\hline 5 & 10.67 & 10.16 & 0 \\
\hline 11 & 1.72 & 0.94 & 4.39 \\
\hline
\end{tabular}




\begin{tabular}{|c|c|c|c|}
\hline \multirow{2}{*}{ Overload Slip Number } & \multicolumn{3}{|c|}{ Overload Capacity(MW) } \\
\cline { 2 - 4 } & Case 1 & Case 2 & Case 3 \\
\hline 19 & 13.04 & 6.54 & 0 \\
\hline 23 & 0 & 0 & 27.79 \\
\hline Summation & 72.93 & 54.91 & 97.95 \\
\hline
\end{tabular}

Table 18. Congestion Eliminating in Normal Operating Condition

\begin{tabular}{|c|c|c|c|c|}
\hline \multirow{2}{*}{$\begin{array}{c}\text { Objective } \\
\text { Function }\end{array}$} & \multicolumn{2}{|c|}{ Single Objective } & $\begin{array}{c}\text { Multi- } \\
\text { objective }\end{array}$ \\
\cline { 2 - 5 } & $f_{1}$ & $f_{2}\left(K_{i}\right)$ & $f_{3}\left(\Delta P_{d i}\right)$ & $F(x)$ \\
\hline $\begin{array}{c}\text { Overload } \\
\text { Capacity }\end{array}$ & 5.792 & 5.794 & 6.413 & 5.318 \\
\hline $\begin{array}{c}\text { Total } \\
\text { Interrupt } \\
\text { Amount }\end{array}$ & 6.587 & 5.860 & 6.522 & 6.117 \\
\hline $\begin{array}{c}\text { Interrupt } \\
\text { Number }\end{array}$ & 2 & 3 & 4 & 2 \\
\hline $\begin{array}{c}\text { Interrupt } \\
\text { Branch }\end{array}$ & 7 & 13 & 18 & 18 \\
\hline
\end{tabular}

Table 19. Congestion Eliminating of Unexpected Power Outage

\begin{tabular}{|c|c|c|c|c|}
\hline \multirow{2}{*}{$\begin{array}{c}\text { Objective } \\
\text { Function }\end{array}$} & \multicolumn{3}{|c|}{ Single Objective } & $\begin{array}{c}\text { Multi- } \\
\text { objective }\end{array}$ \\
\cline { 2 - 5 } & $f_{1}$ & $f_{2}\left(K_{i}\right)$ & $f_{3}\left(\Delta P_{d i}\right)$ & $F(x)$ \\
\hline $\begin{array}{c}\text { Overload } \\
\text { Capacity }\end{array}$ & 6.352 & 6.217 & 6.561 & 6.534 \\
\hline $\begin{array}{c}\text { Total } \\
\text { Interrupt } \\
\text { Amount }\end{array}$ & 6.650 & 6.397 & 6.696 & 6.442 \\
\hline $\begin{array}{c}\text { Interrupt } \\
\text { Number }\end{array}$ & 2 & 3 & 3 & 2 \\
\hline $\begin{array}{c}\text { Interrupt } \\
\text { Branch }\end{array}$ & 13 & 2 & 19 & 13 \\
\hline
\end{tabular}

\section{Conclusion}

(1). The mathematical model constructed in this paper has a total of three objective functions to optimize: interruptible load match with brand circuit overload, the minimum number of interruptible load users and the minimum number of total interrupt amount. After simulating the IEEE-30 bus system, analyzing its calculation result: no matter which optimization objective alone as the objective function of the model, the final selected scheme of interruptible load is not ideal. But the mathematical model presented in this paper can take into account the conditions of the three objectives, making three objective functions achieve an optimal state at the same time.

(2). Analyzing multi-objective model in this paper comprehensively, in the solving method, the evaluation function is introduced. And constructing evaluation function method based on the linear weighted sum is used to optimize the multiobjective problem. This method can transform the multi-objective model into a simple single objective problem by mathematical transformation. Analysis of the simulation calculation results can be seen: constructing evaluation function method 
can consider the three objective conditions, a more comprehensive analysis than the single objective model.

(3). In the selected process of determinating interruptible load scheme, this paper mainly analyzes three cases: first, in normal operating condition of the power system, second, in the condition of power outage caused an unexpected accident, and the third, in the condition that a transmission line node branch suddenly disconnect. In addition to calculating and analyzing the IEEE-30 bus system, this article applies the multi-objective mathematical model to an actual power grid. The torch variable region of this oil grid is carried on the analysis and calculation also according to the above three conditions. Calculation result shows that: multiobjective mathematical model presented in this paper will be able to respond quickly and make the corresponding processing to eliminate the congestion in such conditions, so as to ensure the safe operation of the transmission line.

\section{Conflict of Interest}

The authors confirm that this article content has no conflicts of interest.

\section{References}

[1] E. Baranm, V. Banunarayanan and K. E. Garren, "Equitable Allocation of Congestion Relief Cost to Transactions", IEEE Trans on Power Systems, vol. 15, no. 2, (2000), pp. 579-585

[2] C. Wei, "Transmission congestion studies based on interruptible load", Zhejiang Industrial University, (2009).

[3] G. Lixuan, "On multi-objective planning evaluation function”, Zhangzhou Technical College, vol. 8, no. 4, (2006), pp. 12-15.

[4] K. Jin and G. Lin, "Transmission Congestion Management Technology under Electricity Market", Automation of Electric Power System, vol. 26, no. 14, (2012), pp. 20-39.

[5] K. Xiangqing, "Interruptible Load of participation in the system standby", Xihua University, (2012).

[6] N. Zhang, J. Xu and C. Xue, "Core-shell structured mesoporous silica nanoparticles equipped with pyrene-based chemosensor: Synthesis, characterization, and sensing activity towards $\mathrm{Hg}(\mathrm{II})$ ", Journal of Luminescence, vol. 131, no. 9, (2011), pp. 2021-2025

[7] W. Jianxue,W. Xifan and W. Xiuli, "Interruptible load electricity market research contract model",Chinese Society for Electrical Engineering, vol. 25, no. 9, (2005), pp. 11-16

[8] Y. Limei, Z. Yusong and X. Jianjun, "Transmission Lines Modeling Method Based on Fractional Order Calculus Theory”, TRANSACTIONS OF CHINA ELECTROTECHNICAL SOCIETY, vol. 29, no. 9, (2014), pp. 260-268 
International Journal of Future Generation Communication and Networking Vol. 9, No.10, (2016) 